\title{
Obtention de clones de violettes (Viola odorata) indemnes de virus par culture d'apex méristématique
}

\author{
A Van Caneghem ${ }^{1}$, A Poupet $^{2 *}$, D Beck $^{2}$, E Berling ${ }^{3}$ \\ ${ }^{1}$ Comité économique des plantes à parfum et aromatiques \\ de la région méditerranéeene (Cepparm), Box 116, Min, F-06042 Nice cedex; \\ 2Station de botanique é de pathologié végétale, Inra, BP 2078, F-06606 Antibes cedex: \\ ${ }^{3}$ Groupement régional d'intérêt phytosanitaire (Grisp), 50, avenue de la Salis, F-06600 Antibes, France.
}

(Reçu le 14 septembre 1995 ; accepté le 22 novembre 1996)

\begin{abstract}
Summary - Production of virus free clones of Viola odorata through meristem tip culture. The production of sweet violet (Viola odorata var victoria) on the French Riviera is severely and increasingly damaged by a frequent complex of three viruses: cucumber mosaic virus, bean yellow mosaic virus and viola mottle virus. In this paper a complete scheme for obtaining virus free plants from meristem tip culture is described: - the formulation of a medium containing kinetin, gibberellic acid and indolylacetic acid for the isolation of the meristem tips, the best growth being observed in stirred liquid conditions; - the subsequent propagation through axillary budding by using agar solidified medium containing N6-benzylaminopurin; - the final rooting of plantlets with a low auxin level and their acclimatization in a perlite-peat mixture. Biological and serological tests allowed the identification of two virus free clones which are intensively multiplied. They will be later transferred to a greenhouse protected against the aphid vectors.
\end{abstract}

Viola odorata $=$ sweet violette $/$ meristem tip culture $/$ vegetative propagation $/$ virus free plants

Résumé - Les plantations locales de violettes (Viola odorata var victoria) sont fréquemment contaminées par plusieurs virus : virus de la mosaïque du concombre, de la mosaïque jaune du haricot, viola mottle virus, dont les dommages croissants menacent la qualité de la production et sa pérennité. Nous décrivons dans cette étude une méthode complète de «régénération » des clones de violette virosés par culture d'apex méristématique : isolement et développement des explants primaires en conditions liquides agitées avec des milieux de culture renfermant de la kinétine, de l'acide gibbérellique et de l'acide indol-acétique ; multiplication végétative par bourgeonnement axillaire dans des milieux de culture solides enrichis en N6-benzylaminopurine; enracinement en présence de faibles concentrations d'auxine et acclimatation des vitroplants obtenus dans un substrat tourbe-perlite. Des épreuves d'état sanitaire, biologique et immunologique, appliquées aux clones obtenus ont permis l'isolement de deux clones apparemment indemnes de virus qui sont actuellement rapidement multipliés en vue de la reconstitution des plantations. Cette démarche est indissociable des mesures prophylactiques pour limiter la recontamination des plants par les insectes vecteurs.

Viola odorata violette / culture de méristèmes / multiplication végétative / élimination des virus

* Correspondance et tirés à part.

Tél : (33) 0493678875 ; fax : (33) 0493678888 


\section{INTRODUCTION}

La culture de violette (Viola odorata) est limitée en France métropolitaine à deux zones :

- la région toulousaine où quelques producteurs cultivent la violette double ( $V$ odorata var parmensis) ;

- le littoral méditerranéen, notamment à Tourrettes-sur-Loup et sa périphérie qui assure la plus grande part de la production nationale ( $V$ odorata var victoria).

Dans ce dernier site la rentabilité des exploitations est assurée par trois formes de valorisation distinctes mais indissociables:

- d'une part, les fleurs récoltées sont conditionnées en bouquets et commercialisées d'octobre à mars sur le marché local et international ;

- d'autre part, les feuilles fauchées en deux coupes (mai et juillet) alimentent les parfumeurs de la région de Grasse qui en extraient les principes aromatiques ;

- enfin, selon les fluctuations du marché, une partie de la récolte florale équeutée est destinée à la confiserie.

Cette production qui peut paraître marginale présente néanmoins une importance locale indiscutable.

En effet ces produits à forte valeur ajoutée génèrent un chiffre d'affaires global voisin de sept millions de francs, un tiers provenant de leur usage comme plante à parfum $(220 \mathrm{t}$ de feuilles en 1991), les deux autres tiers étant issus de la vente des 27 millions de tiges.

En dépit d'un contexte économique favorable persistance de la demande industrielle, intérêt non démenti des particuliers pour les fleurs et succès croissant de la confiserie -, cette culture est actuellement en régression, les surfaces cultivées ayant diminué d'un tiers depuis une douzaine d'années. Ce déclin peut être imputé pour une part importante à des facteurs d'ordre sanitaire (Desportes et al, 1979). En effet cette plante multipliée végétativement par éclatement de touffes ou bouturage de stolons est sujette à une « dégénérescence » observée de longue date, causée par un complexe de virus le plus souvent associés : viola mottle virus VMV (Poupet et Marais, 1974), virus de la mosaïque jaune du haricot BYMV (Provvidenti et Granett, 1974), virus de la mosaïque du concombre (Valverde, 1984).

La possibilité d'éliminer les virus par culture de méristème (Morel et Martin, 1952), technique souvent employée dans le cas de plantes horticoles, avait été évaluée dans les années 1975 par quelques essais préliminaires (Beck, résultats non publiés).

Face à l'aggravation des dommages imputables aux virus cités (déformations et mosaïques foliaires, nanisme et panachures des fleurs) causant une sévère dépréciation de la valeur commerciale et suite à l'introduction croissante de culture hors sol pouvant valoriser au mieux un matériel végétal éventuellement « régénéré », l'hypothèse précédente a été réexaminée.

Peu de données bibliographiques existent quant aux capacités d'organogenèse in vitro d'espèces du genre Viola : aptitude à la callogenèse de tissus de Pensée ( $V$ tricolor) (Babber et Kulbhushan, 1991), obtention de vitroplants de $V$ odorata var parmensis, sans indication de la méthodologie précise utilisée (Morard et Henry, 1994).

Dans le présent article nous décrivons les résultats obtenus depuis 1990 concernant l'isolement de clones apparemment indemnes de virus à partir d'apex méristématiques, leur multiplication végétative in vitro et les conditions de leur culture ex vitro.

\section{MATÉRIELS ET MÉTHODES}

\section{Matériel végétal : mise en culture d'apex méristématiques}

Environ 250 plants de $V o$ var victoria ont été prélevés à la fin de l'hiver 1990 dans différentes parcelles des plantations de Tourrettes-sur-Loup. Transplantés en serre dans des pots individuels contenant du porphyre de l'Estérel, ils ont reçu périodiquement un traitement de fertirrigation.

S'agissant d'une espèce acaule, les organes végétatifs (méristèmes, stolons) sont en contact étroit avec le sol et la technique de culture individuelle en substrat inerte a été présumée abaisser les taux de contaminations bactériennes ou fongiques lors des mises en culture initiales.

L'examen visuel des plantes et des épreuves d'indexage biologique pratiquées sur des échantillons ont confirmé la présence des trois virus précités dans la collection de pieds mères.

Les prélèvements d'apex méristématiques, qui ont débuté en avril 1990 s'effectuent sous loupe binoculaire, sans désinfection préalable, par l'excision de l'extrémité apicale d'un stolon. Les explants, d'une taille moyenne de $150 \mu \mathrm{m}$, comportent le dôme apical proprement dit et un primordium foliaire.

Entre avril 1990 et mars 1991, plus de 1000 apex méristématiques, à raison de lots de 50 explants, ont été prélevés et mis en culture dans des tubes à hémolyse 
$(12 \times 75 \mathrm{~mm})$ fermés avec du coton et un film de polyéthylène, recevant chacun $2 \mathrm{~mL}$ de l'un de trois milieux de culture différents (D1, D2, D3).

Le milieu de culture de base (MB) contient les éléments minéraux de Murashige et Skoog (Murashige et Skoog, 1962) dans lesquels la concentration de nitrate d'ammonium est réduite à $800 \mathrm{mg} / \mathrm{L}$, un complexe vitaminique ( $1 \mathrm{mg} / \mathrm{L}$ de cystéine, chlorhydrate de thiamine, pyridoxine, pantothénate de calcium, acide nicotinique), myoinositol (100 mg/L), acide ascorbique (50 $\mathrm{mg} / \mathrm{L}$ ), Fe EDTA (27 mg/L), acide gibbérellique (GA3 $1 \mathrm{mg} / \mathrm{L})$, fructose $40 \mathrm{~g} / \mathrm{L}$, agar $7 \mathrm{~g} / \mathrm{L}(\mathrm{pH} \mathrm{5,8})$.

Les milieux D1, D2, D3 contiennent, outre les éléments précédents, respectivement 0,1 et $0,5,0,1$ et 1,1 et $1 \mathrm{mg} / \mathrm{L}$ d'acide indolacétique et de kinétine.

Le milieu D2, dépourvu d'agar, a également été éprouvé dans des tubes à essais $(16 \times 160 \mathrm{~mm})$ placés sur un agitateur rotatif (1/6 tour par minute).

Tous les tubes de culture sont conservés dans les conditions suivantes :

- durée d'éclairement quotidien : $16 \mathrm{~h}$ :

- température diurne : $23 \pm 1{ }^{\circ} \mathrm{C}$, nocturne : $18 \pm 1{ }^{\circ} \mathrm{C}$

- rayonnement de $5 \mu \mathrm{M} / \mathrm{m}^{-2} / \mathrm{s}^{-1}$ fourni par des tubes fluorescents Philips TLD $36 \mathrm{~W}$.

\section{Multiplication}

Les plantules obtenues à l'issue de la phase précédente sont transférées dans des tubes de culture de $25 \times 150 \mathrm{~mm}$ obstrués par des bouchons en polycarbonate afiplastex, contenant $10 \mathrm{~mL}$ d'un milieu de multiplication (M).

Au milieu de base indiqué précédemment (MB) sont ajoutés $1 \mathrm{mg} / \mathrm{L}$ de N6-benzylaminopurine et $0,1 \mathrm{mg} / \mathrm{L}$ d'acide indolacétique : ce milieu unique a été utilisé car il avait fourni des résultats prometteurs lors des essais antérieurs. Les conditions sont identiques à celles indiquées précédemment, hormis le rayonnement porté à $50 \mu \mathrm{M} / \mathrm{m}^{-2} / \mathrm{s}^{-1}$.

\section{Enracinement, acclimatation, épreuves d'état sanitaire}

Les explants issus de la phase de multiplication sont isolés et placés dans des tubes renfermant $10 \mathrm{~mL}$ de milieu de culture dépourvu de régulateur de croissance (R0) ou contenant 0,01 (R1) ou $0,05 \mathrm{mg} / \mathrm{L}$ (R2) d'acide indolacétique, le milieu de base (MB) étant dilué de moitié. Les conditions restent identiques à celles de la phase de multiplication. Après $30 \mathrm{j}$ sur le milieu d'enracinement approprié (voir Résultats) les plantules d'une taille de $35-40 \mathrm{~mm}$, comportant 3 à 4 feuilles et un système radiculaire bien développé, sont transférées dans des pots individuels contenant un mélange à parts égales de perlite et de tourbe, placés dans une chambre de culture isolée. Une atmosphère en condition d'humidité saturante doit être maintenue pendant au moins
$10 \mathrm{j}$ et les plants sont conservés à $23 \pm \mathrm{I}{ }^{\circ} \mathrm{C}$ sous un rayonnement de $50 \mu \mathrm{M} / \mathrm{m}^{-2} / \mathrm{s}^{-1}$.

Après $30 \mathrm{j}$ les individus sont placés dans une serre protégée des recontaminations par les insectes vecteurs et sont utilisés pour les épreuves d'état sanitaire effectuées selon deux protocoles différents :

- broyage des feuilles dans un tampon Tris 0,05 M pH 7 ( $1 \mathrm{~mL} / \mathrm{g} \mathrm{MF})$ et inoculation à des plants de Chenopodium quinoa, élevés à $23 \pm 1{ }^{\circ} \mathrm{C}$ dans une enceinte climatisée recevant un rayonnement de $150 \mu \mathrm{M} / \mathrm{m}^{-2} / \mathrm{s}^{-1}$;

- détection immunoenzymatique (méthode Elisa) des trois virus recherchés (VMV, BYMV et CMV) en utilisant des réactifs immunologiques fournis par la firme SANOFI ou réalisé localement (VMV).

\section{RÉSULTATS - DISCUSSIONS}

\section{Développement des apex méristématiques}

En une quinzaine de jours seule la combinaison hormonale kinétine $1 \mathrm{mg} / \mathrm{L}$, acide gibbérellique $1 \mathrm{mg} / \mathrm{L}$ et acide indole acétique $0,1 \mathrm{mg} / \mathrm{L}$ (milieu D2) a permis le développement d'un nombre significatif d'explants. Dans le même temps un taux de contamination bactérienne ou fongique négligeable a pu être noté. Les autres combinaisons ont conduit à la nécrose des apex sans aucun signe d'évolution. Il est à noter que les meilleurs résultats ont été obtenus en utilisant le milieu liquide maintenu en agitation : ces conditions permettent l'obtention de pousses feuillées de 8-10 $\mathrm{mm}$ comportant une paire de feuilles en 3 semaines (fig 1A); un début de développement a été possible avec le même milieu solidifié par l'agar mais les bourgeons n'ont pu poursuivre leur développement. Il est intéressant d'observer que le même milieu solide avait permis l'obtention de pousses feuillées lors des premiers essais entrepris il y a une quinzaine d'années. Dans l'intervalle les techniques culturales ont radicalement changé : introduction de la culture hors sol, programmes de fertilisation, usage de désherbants peu sélectifs : à cet égard le fait qu'une croissance convenable des méristèmes n'ait été observée qu'en conditions liquides agitées peut suggérer qu'un "lessivage » des explants a permis la dilution ou l'excrétion de molécules inhibitrices de la croissance, présentes dans les tissus parentaux. Cette hypothèse peut, en partie, expliquer le très faible rendement de cette phase initiale puisqu'une dizaine de pousses feuillées ont été obtenues à partir des apex méristématiques mis en culture, toutes issues de la culture en milieu liquide. 

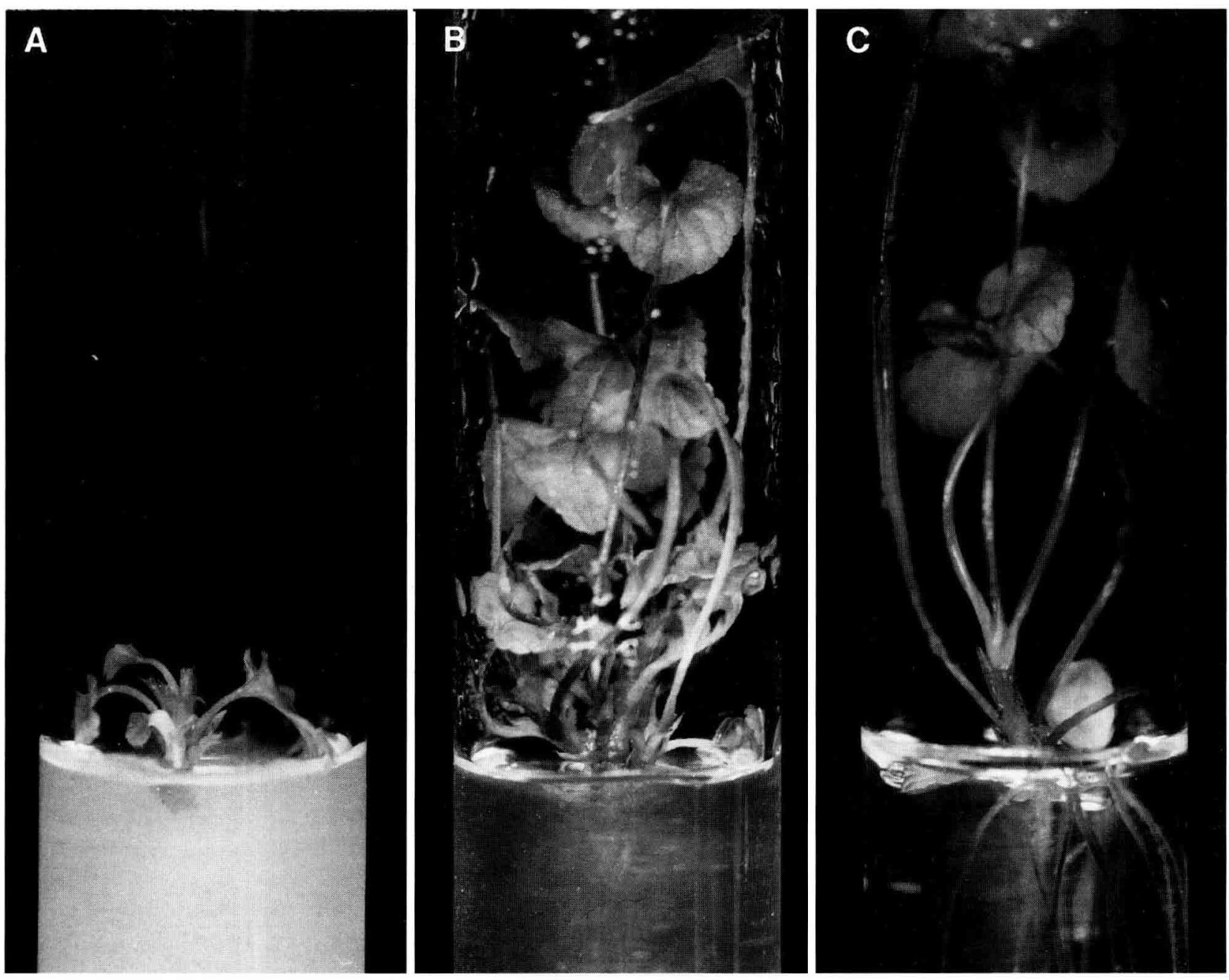

Fig 1. A. Aspect d’une pousse feuillée de violette après trois semaines de culture sur le milieu de développement des apex méristématiques. B. Souche de violettes à l’issue d’un cycle de multiplication. C. Plant enraciné de violette prêt à être acclimaté.

\section{Multiplication des pousses feuillées}

Les pousses feuillées obtenues, identifiées et constituant autant de clones initiaux, sont placées sur le milieu de multiplication $\mathrm{M}$ : après trois subcultures de 30 jours, on peut observer l'installation

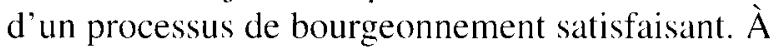
l'aisselle de chaque feuille, au lieu d'insertion sur l'axe caulinaire contracté, on peut noter le développement de nouveaux bourgeons d'une taille de 12 à $15 \mathrm{~mm}$. comportant une paire de feuilles (fig 1B) et ne présentant aucune déformation ou anomalie apparentes. Pendant quatre subcultures ultérieures ce taux mensuel de multiplication s'est révélé constant sans symptôme d'évolution défavorable : réduction de taille des bourgeons, turgescence exagérée des tissus ou enracinement spontané. Ce sont ces conditions qui ont été retenues pour l'amplification des souches avant les essais d'enracinement.

\section{Enracinement des pousses et acclimatation des individus}

Des lots d'une vingtaine d'individus des divers clones ont été placés sur les trois milieux d'enracinement R0, R1 et R2. Après 3 semaines, seul le milieu RI s'est révélé efficace tant par la qualité de l'enracinement (plusieurs racines blanches, grêles, rapidement ramifiées) (fig 1C) que par le rendement toujours supérieur à $90 \%$.

Sur le milieu Ro dépourvu de régulateur de croissance, moins de $50 \%$ des individus sont enracinés après 4 semaines ; à l'inverse une concentration d'auxine de $0,05 \mathrm{mg} / \mathrm{L}$ (milieu R2) se révèle très rapidement excessive car elle induit la formation de cals bruns à la base de l'explant, accompagnée du jaunissement et de l'abcission des feuilles. Il semble donc que dans nos conditions expérimentales, les clones de violettes soient très sensibles à un excès d'auxine mais que 
celle-ci, à très faible dose, soit indispensable pour assurer un enracinement satisfaisant.

En ce qui concerne les essais d'acclimatation, les taux de reprise sont voisins de $100 \% ; 3$ mois après la mise en culture ex vitro des plantules, les premières fleurs apparaissent mais ce n'est qu'après 12 mois de culture, après un développement suffisant des touffes qu'une récolte de fleurs peut être envisagée, conforme à la pratique horticole.

En conclusion des travaux concernant les capacités d'organogenèse in vitro sensu stricto des clones de violettes étudiés, nous avons montré qu'il est possible :

- d'obtenir des individus à partir d'apex méristématiques, l'usage de milieux liquides agités étant le plus approprié ;

- de multiplier et d'amplifier les souches avec un taux de multiplication régulier et satisfaisant conduisant à des individus présentant une structure normale ;

- d'enraciner les plants obtenus avec un excellent rendement, pour peu qu'on utilise des milieux de culture appauvris en éléments minéraux et en régulateur de croissance ;

- d'acclimater les plants avec un pourcentage de reprise très élevé.

C'est la séquence milieu de développement des apex D2, milieu de multiplication M, milieu d'enracinement R1 qui a été utilisée pour produire le matériel végétal soumis, après acclimatation, aux épreuves d'état sanitaire. Au stade de développement des plantes où ces dernières ont été pra- tiquées, bien qu'aucun symptôme visuel n'apparaisse sur les feuilles, seuls les individus issus de deux clones se sont révélés apparemment indemnes de toute contamination virale à l'issue des épreuves biologiques et sérologiques. Un second contrôle, pratiqué 3 mois plus tard a confirmé ces résultats. En revanche, les premiers symptômes de mosaïque foliaire sont apparues dans les individus encore contaminés 4 mois après leur sortie des tubes de culture. Rapporté à la population totale d'apex initiaux mis en culture, le nombre de clones " guéris » apparaît dérisoire mais est plus acceptable compte tenu du rendement très faible de la phase initiale. Seuls les deux clones considérés comme indemnes de virus ont été multipliés in vitro et permettent actuellement la reconstitution progressive des plantations.

Plusieurs milliers d'individus de chaque clone ont été produits (fig 2) et toutes les observations relatives à leurs performances agronomiques développement, qualité du feuillage et des fleurs, aptitude au bouturage... devraient faire l'objet de prochaines notes de la part des divers intervenants professionnels et interprofessionnels de ce programme.

Des travaux complémentaires restent néanmoins nécessaires:

- analyser de façon plus approfondie les causes des difficultés de développement des apex méristématiques ;

- mesurer la vitesse de recontamination éventuelle des parcelles plantées d'individus « régénérés » : des indications préliminaires semblent indiquer qu'une recontamination partielle par le virus de la

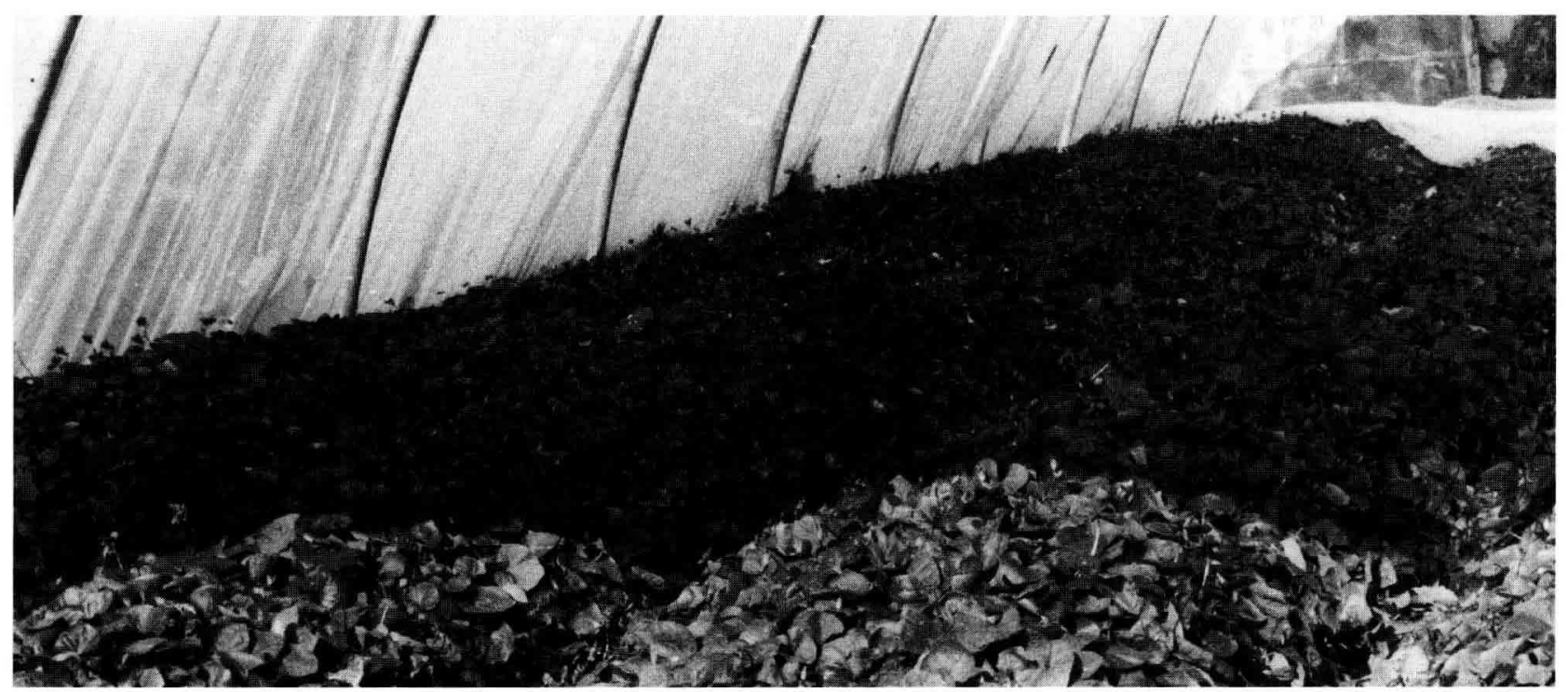

Fig 2. Plants de violette « régénérés » cultivés en tunnel. Les différences de tons sont dues à l’éclairement. 
mosaïque du concombre n'est pas exclue dès la première année, après le transfert des plants dans des tunnels plastiques. Il est clair que le contrôle des populations d'aphides vecteurs ainsi que des mesures de prophylaxie sont impératifs pour tirer le meilleur parti - en l'occurence la meilleure longévité - du matériel « régénéré ».

Cette exigence s'impose particulièrement dans la perspective de la mise en place d'un schéma de certification des plants actuellement en cours.

\section{REMERCIEMENTS}

Ces travaux, entrepris à la demande du Cepparm (Comité économique des plantes à parfum et aromatiques de la région méditerranéenne) ont bénéficié de l'aide de l'Onippam (Office national interprofessionnel des plantes à parfum, aromatiques et médicinales). La prémultiplication in vitro et l'acclimatation en serre des plants régénérés a été réalisée avec le concours de l'IFHP (Station nationale d'expérimentation, La Gaude F-06610. L'évaluation de l'état sanitaire (indexages biologiques et tests Elisa) et la réalisation de certains réactifs ont été effectuées par le Grisp. Les observations préliminaires en serre et en champ sont dues au Creat (Centre de recherches économiques et d'action technique, La Gaude, F-06610). Qu'ils en soient remerciés.

\section{RÉFÉRENCES}

Babber S, Kulbhushan S (1991) Study of anatomy of vitrified structure in Viola tricolor. Ann Biol 7, 9395

Desportes L, Gilly G, Cuany A, Mercier S, Poupet A, Marais A (1979) Contribution à l'étude de quelques problèmes techniques posés par la culture de la violette. PHM Rev Hortic 200, 13-21

Morard P, Henry M (1994) Culture in vitro et culture hors sol de la violette de Toulouse. PHM Rev Hortic $348,21-28$

Morel G, Martin C (1952) Guérison de dalhias atteints d'une maladie à virus. C R Acad Sci 235, 1324-1325

Murashige T, Skoog F (1962) A revised medium for rapid growth and bioassays with tobacco tissue culture. Physiol Plant 15, 473-497

Poupet A, Marais A (1974) Le virus 2 de la violette. CR Journées de phytiatrie - Phytopharmacie circum méditerranéennes. Montpellier 15-18 septembre 1974

Provvidenti R, Granett AL (1974) Sweet violet, a natural host of bean yellow mosaic virus. Plant Dis Rep $58,155-156$

Valverde RA (1984) Unusual strain of cucumber mosaic virus causing flower-breaking symptoms in wild violets. Plant Dis Rep 68, 913-915 